\title{
Green Synthesis of Nickel Oxide Nanoparticles using Populus ciliata Leaves Extract and their Potential Antibacterial Applications
}

\author{
Muhammad Hafeez ${ }^{*}$ (iD), Ruzma Shaheen ${ }^{1}$ (iD), Bilal Akram² (iD, Muhammad Naeem Ahmed ${ }^{1}$ (iD, Zain-ul-Abdin ${ }^{1}$ (i),

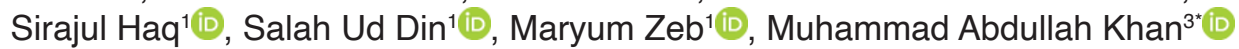 \\ ${ }^{1}$ Department of Chemistry, University of Azad Jammu \& Kashmir, Muzaffarabad 13100, Azad Kashmir, Pakistan. \\ ${ }^{2}$ Department of Chemistry, Tsinghua University, Beijing 100084 People's Republic of China. \\ ${ }^{3}$ Department of Environmental Sciences, Quaid-i-Azam University, Islamabad 45320, Pakistan
}

Received 17 April 2020, revised 25 June 2021, accepted 17 July 2021

\begin{abstract}
Green synthesis of nanoparticles has received a lot of attention from scientists globally because it is eco-friendly, relatively rapid, and a cost-effective method. This work presents a method for the green synthesis of nickel oxide nanoparticles (NiO-NPs) using leaf extracts of Populus ciliata as a reducing and stabilising agent. The synthesised NiO-NPs were characterised by ultravioletvisible spectroscopy, Fourier transform infrared spectroscopy, powder X-ray diffraction, scanning electron microscopy, and transmission electron microscopy. It was found that the synthesised NiO-NPs shapes varied, were highly crystalline, and had a face-centred cubic geometry. The calculated crystallite size of the synthesised nanoparticles was $44 \mathrm{~nm}$. Moreover, the antibacterial activity of the synthesised NiO-NPs was also conducted against Gram-positive bacteria (Bacillus subtilis, Bacillus licheniformis) and Gram-negative bacteria (Escherichia coli and Klebsiella pneumoniae). Bacillus subtillus showed a maximum inhibition zone of $28.1 \pm 1.6 \mathrm{~mm}$, whereas Klebsiella pneumonia showed a minimum inhibition zone of $9.2 \pm 0.5 \mathrm{~mm}$. It was also found that the antibacterial activity increased with an increase in the concentration of NiO-NPs.
\end{abstract}

KEYWORDS

antibacterial activity, green synthesis, nanoparticles, NiO, Populus ciliata.

\section{Introduction}

Recently, the synthesis or fabrication of metal oxide nanoparticles (NPs) has received a great amount of attention from scientists globally. ${ }^{1-2}$ These NPs bear unique properties (e.g. biological, mechanical, thermal, electrical, catalytic, and optical properties) compared to bulk materials with similar chemical compositions. Metal oxide NPs are often used in biomedical sciences, optics, drug delivery, optoelectronic devices, bio-sensing, catalysis, antimicrobial activities, and chemical sensors. ${ }^{4-7}$

Several research groups are working on the synthesis of metal oxide NPs. Different synthesis procedures have been reported in the literature to synthesise NiO-NPs, including; hydrothermal, solvothermal, microwave-assisted, thermal decomposition, precipitation-calcination, chemical precipitation, and thermal decomposition. ${ }^{8-11}$ These synthetic methods have certain limitations, such as using toxic chemicals, long reaction times, and production of hazardous byproducts. Moreover, the toxic chemicals used during such synthetic procedures remain on the surface of NPs, and such NPs cannot be used for biomedical applications. Green synthesis can use bacteria, fungi or plant extracts to synthesise metal-based NPs. ${ }^{12-14}$ Plant extract-based methods are usually low-cost and require less time to synthesise NPs. These methods usually involve one-step reaction procedures and are environmentally friendly. Such attributes make these methods the preferable choice for the synthesis of NPs. ${ }^{15-18}$

The research community has reported widely on the use of $\mathrm{NiO}-\mathrm{NPs}$ in different biomedical applications. TheseNPs have been used as an antifungal and as antibacterial agents. They are

*To whom correspondence should be addressed

Email:_muhammadhafeezchemist@gmail.com, abdullah42pk@gmail.com also used in different cancer cell lines. ${ }^{19-24}$ These applications of $\mathrm{NiO}-\mathrm{NPs}$ are due to their cytotoxic activity and useful biological properties. It has been found that NiO-NPs release $\mathrm{Ni}^{2+}$ ions, which causes oxidative stress in bacterial cells and results in cell death. ${ }^{25-27}$ The antibacterial properties of the NiO-NPs are also attributed to the slow release of $\mathrm{Ni}^{2+}$ and its stability in an aqueous medium. Generally, the smaller-sized NiO-NPs are more effective against pathogens, and their pathogen-killing activity depends on the medium used to synthesise the NPs. In terms of antibacterial activity, $\mathrm{NiO}-\mathrm{NPs}$ are effective against both Gram-positive and Gram-negative bacterial species. NiONPs have also shown good anti-inflammatory properties in human cells. ${ }^{28}$

A few reports have been found on the use of certain plant materials for the synthesis of NiO-NPs. The extracts of plants such as Aegle marmelos, Ocimum sanctum, Calotropis gigantean, Tamarix serotina, hibiscus, Annona squamosa, and Rambutan (Nephelium lappaceum) have been used for the synthesis of $\mathrm{NiO}$ NPs with variable sizes and morphologies. ${ }^{29-36}$ The successful synthesis of NiO-NPs using the aforementioned extracts has also shown the potential of these plants' phytochemicals to stabilise the synthesised NPs. ${ }^{29-36}$ Populus ciliata belongs to the Salicaceae family, and this plant is native to Indo-Pak and is commonly known as Himalayan poplar. ${ }^{37-38}$ This woody plant may attain a height up to $50 \mathrm{~m}$. The wood of this plant is used for making furniture, and its bark has many medicinal uses. ${ }^{37-38}$ However, the leaves of this plant mostly remain as bio-waste but could be used beneficially to fabricate metal-based NPs. To the best of our knowledge, the extracts from the leaves of this plant have not yet been employed to synthesise NiO-NPs. ${ }^{37-38}$ The present work describes the use of Populus ciliata to synthesise small-sized NiO-NPs, their subsequent characterisation, and antibacterial properties. 


\section{Materials and Methods}

Nickel nitrate hexahydrate $\left(\mathrm{NiNO}_{3} \cdot 6 \mathrm{H}_{2} \mathrm{O}\right)$ was purchased from $\mathrm{BDH}$ England and was used without further purification. Fresh and healthy leaves of Populus ciliata were collected from the University of Azad Jammu and Kashmir, main campus, Muzaffarabad, Pakistan.

\subsection{Preparation of leaf extract}

The collected leaves of Populus ciliata were washed with tap water, followed by washing with doubly distilled water to remove the associated debris prior to their use. The washed leaves were dried at ambient temperature. These leaves were finely chopped. Then $10 \mathrm{~g}$ of these chopped leaves were added to $100 \mathrm{ml}$ of distilled water, and the resulting mixture was heated (to boiling) for 2 hours. During this heating, the transparent mixture changed to a light brown-coloured mixture (Figure 1). The extract obtained was filtered using Whatmann ${ }^{\circledR}$ filter paper and then stored in a refrigerator $\left(4^{\circ} \mathrm{C}\right)$ until further use.

\subsubsection{Synthesis of $\mathrm{NiO}-\mathrm{NPS}$}

The salt, $\mathrm{NiNO}_{3} \cdot 6 \mathrm{H}_{2} \mathrm{O}$, was used as a precursor to fabricate the NiO-NPs. A $1 \mathrm{mM}$ salt solution was prepared by dissolving $291.0 \mathrm{mg}$ of $\mathrm{NiNO}_{3} \cdot 6 \mathrm{H}_{2} \mathrm{O}$ in $100 \mathrm{ml}$ of distilled water. For the synthesis of NiO-NPs, $30 \mathrm{ml}$ of $1 \mathrm{mM}$ nickel salt solution and $20 \mathrm{ml}$ of the extract from the plant leaves were heated at $80^{\circ} \mathrm{C}$ for 4 hours. During this heating, the colour changed from light brown to dark brown, which indicated the formation of $\mathrm{NiO}$ NPs. The synthesised NPs were purified by centrifugation at $25000 \mathrm{rpm}$. The purified NiO-NPs were dried at $60^{\circ} \mathrm{C}$.

\subsubsection{Characterisation}

The synthesised NiO-NPs were characterised using different techniques. Fourier transform infrared (FTIR)-spectra were obtained (in the range of $400-4000 \mathrm{~cm}^{-1}$ ) using a Shimadzu $8400 S$ spectrophotometer. Powder XRD analysis was done using a D8 Advance $\mathrm{X}$-ray diffractometer using $\mathrm{Cu} \mathrm{K} \alpha$ radiation $(\lambda=1.5418$ Á). Scanning electron microscopy (SEM)/energy dispersive X-ray (EDX) analysis of the NiO-NPs was carried out using an FEI NOVA nano SEM 450 equipped with an Oxford EDX detector. Transmission electron microscopy (TEM) was carried out using Field Electron and Ion Company (FEI) Tecnai G2 F20 S-Twin microscope.

\subsubsection{Antibacterial Activities}

Agar well diffusion method was used for the investigation of the antibacterial activities of the NiO-NPs. For this purpose, $\mathrm{NiO}-\mathrm{NPs}$ solutions of three different concentrations $\left(2 \mathrm{mg} \mathrm{ml}^{-1}\right.$, $4 \mathrm{mg} \mathrm{ml}^{-1}$ and $8 \mathrm{mg} \mathrm{ml}^{-1}$ ) were prepared in water. Then $50 \mu \mathrm{l}$ of each solution was applied on bacterial strain plates in the presence of a control drug (bacitracin). Incubation was done at $37^{\circ} \mathrm{C}$ for 24 hours. The zone of inhibition (ZOI) was measured in

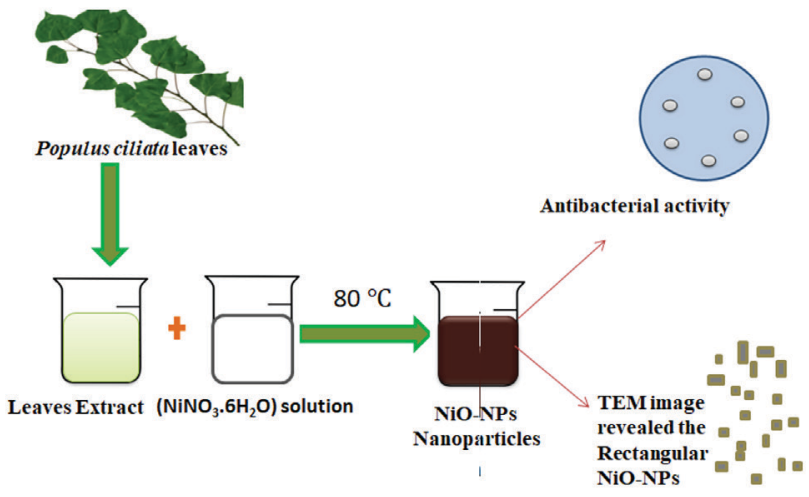

Figure 1. Graphical representation of the synthesis of NiO-NPs. millimetres (mm). One-way ANOVA, with Dunnett's multiple comparison test software, was employed for statistical analysis.

\section{Results and Discussion}

\subsection{The mechanism for the formation of NiO-NPs}

It has been reported that the phytochemicals present in the extracts from the leaves are responsible for the reduction of metals ions into neutral metal atoms (Figure 2). ${ }^{32}$ The good reduction potential of chloride, nitrate, and sulphate salts of the metals, including nickel salts, has been reported. This reduction potential is due to the attachment of the metal centres with these electron-donating anions. ${ }^{32}$ Consequently, the electron density on the conjugate salts of the metals increases. As a result, metals in the ionised form detach from their anions and are reduced into the stable form using phytochemicals from the leaf extracts ${ }^{22}$. The phytochemicals from plant extracts such as terpenoids, alkaloids, flavonoids and polyphenols act as chelating agents to reduce the metals into the zero oxidation state. Since the synthesis was carried out in the air, the neutral $\mathrm{Ni}$ atoms were oxidised to $\mathrm{NiO} .^{32}$

\subsection{UV-Visible spectroscopy}

The synthesised NiO-NPs were characterised by UV-visible spectroscopy (Figure 3). The reduction of the nickel nitrate solution to NiO-NPs was analysed by UV-visible spectroscopic studies in the range of $400-800 \mathrm{~nm}$. The absorption peak observed at $333 \mathrm{~nm}$ clearly indicated the successful formation of NiO-NPs. The sample exhibited a strong absorption peak in the UV region, which was blue-shifted from the absorption edge of bulk $\mathrm{NiO}$. Other researchers have also reported similar absorption peaks. ${ }^{24}$ The UV-Visible spectra and surface plasmon resonance (SPR) wavelengths were sensitive to the characteristics of the NiO-NPs. UV absorption studies have also

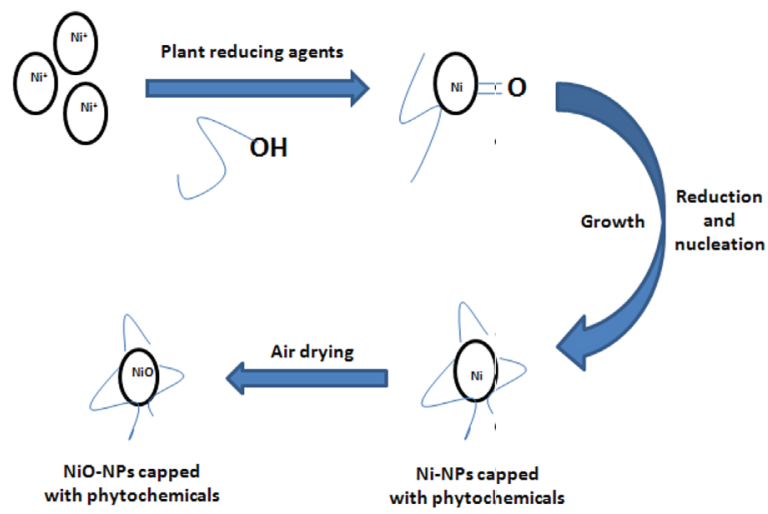

Figure 2 Proposed mechanism for the formation of NiO-NPs. ${ }^{32}$

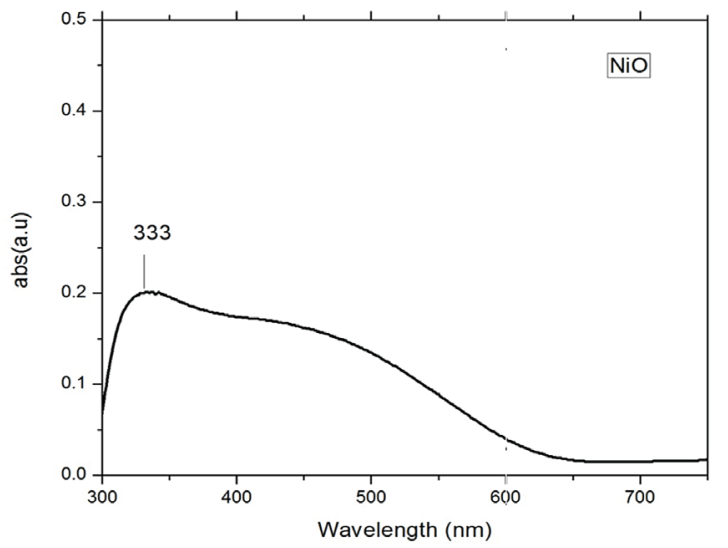

Figure 3. The UV-Visible spectrum of NiO-NPs. 
been reported by various other researchers..$^{20,23,24,32}$ Nasseri et al. ${ }^{31}$ observed the peak maxima at $296 \mathrm{~nm}$ and have attributed this peak to the Ni-O bond. The position of the exciton absorption for $\mathrm{NiO}-\mathrm{NPs}$ depends on several factors such as temperature, synthetic method, size and shape of NPs. Din et al. have studied the UV-Visible spectra of NiO-NPs, and have found the peak maxima at $400 \mathrm{~nm} .^{22}$

\subsection{FT-IR spectroscopy}

The FT-IR spectroscopy was performed to analyse the functional groups present on the biomolecules in the leaf extract of Populus ciliata (Figure 4). The prominent peaks were observed at 3438, 2958,1612, 1381, 1093, 1022 and $623 \mathrm{~cm}^{-1}$. The peak at $3438 \mathrm{~cm}^{-1}$ represented the hydroxyl group of alcohols or phenols. The absorption peak at $2958 \mathrm{~cm}^{-1}$ could be assigned to the $-\mathrm{CH}$ stretching vibrations of $-\mathrm{CH}_{2}$ and $-\mathrm{CH}_{3}$ groups. Another peak at $1381 \mathrm{~cm}^{-1}$ represented the $\mathrm{NO}_{3}^{-1}$ group. The peak at $1612 \mathrm{~cm}^{-1}$ indicated the $\mathrm{C}=\mathrm{O}$ group of tertiary amides. The peak at $623 \mathrm{~cm}^{-1}$ could be attributed to nickel oxide (NiO). The reduction of precursor salt by plant biomolecules under mild conditions led to the formation of NiO-NPs. The results showed that these moieties (especially the $\mathrm{OH}$ group) helped to stabilise the NPs. Similar functional groups have also been reported in the FT-IR spectrum of synthesised NiO-NPs using different synthetic procedures. ${ }^{20,22,23,25,31,32,35}$

\subsection{X-Ray Diffraction Microscopy}

The powder XRD patterns of the synthesised NiO-NPs presented in Figure 5 showed diffraction peaks at $2 \theta$ values of $37.2^{\circ}, 43.2^{\circ}, 62.8^{\circ}, 75.4^{\circ}$, and $79.3^{\circ}$, which correspond to $h k l$ values of (111), (200), (220), (311), and (222). These diffraction peaks matched the face-centred cubic (fcc) crystal system (reference card No. 04-0835). The narrow and rather sharp diffraction peaks confirmed the synthesis of crystalline NiONPs, whereas the average crystallite size of NPs, calculated using the Debye-Scherrer equation, was $44 \mathrm{~nm}$. No other peaks were observed in the XRD pattern, which showed the purity of the synthesised NPs. Our results match those already reported in the literature. ${ }^{20,23,32}$

\subsection{SEM and TEM analysis}

The structural features of the synthesised NiO-NPs were investigated through electron microscopy. The SEM image (Figure 6a) showed that the NPs were mostly interconnected, while a small fraction of the NPs merged to form larger particles (Figure 6b). Such behaviour of particles was due to the agglomeration of the small-sized particles. Normally, small-sized particles agglomerate, decrease their surface energy and hence become more stable. TEM image (Figure 6c) showed the formation of reasonably spherical particles at low resolution. However, high-resolution TEM images (insert in Figure 6c) revealed that the size and shape of the NPs varied. Although most of the particles were interconnected, some NPs with visible boundaries could be seen clearly. The agglomeration of the smaller particles might be due to several factors, for example, low surface energy. In addition, the NP scan also interconnect through weak van der Waals forces. Also, a huge amount of heat produced during TEM measurements can result in the combination of the smaller NPs. Several researchers have already reported such agglomeration of the NPs during TEM measurement. ${ }^{20,22,23,31}$ The average particle size estimated from TEM image analysis and presented in the histogram (Figure 6d) is around $58 \mathrm{~nm}$.

\subsection{EDX Analysis}

The elemental composition of the NiO-NPs was confirmed using EDX analysis. The EDX spectrum revealed the presence of predominantly nickel and oxygen peaks along with traces of

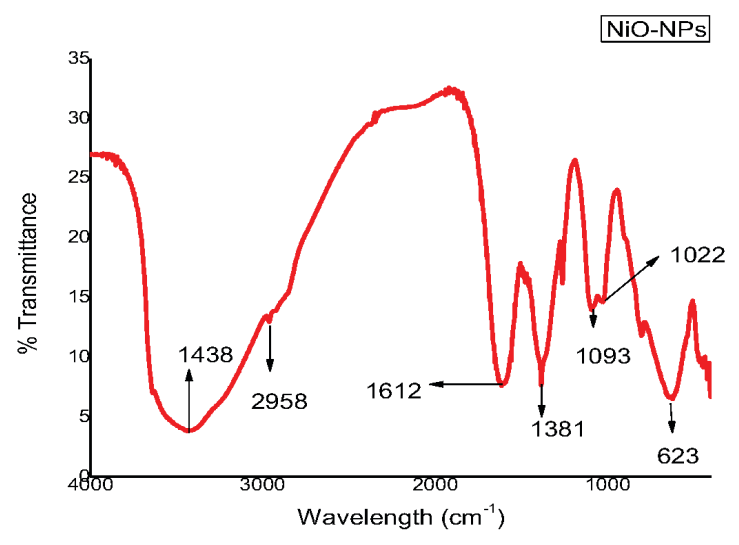

Figure 4. FT-IR spectrum of synthesised NiO-NPs.

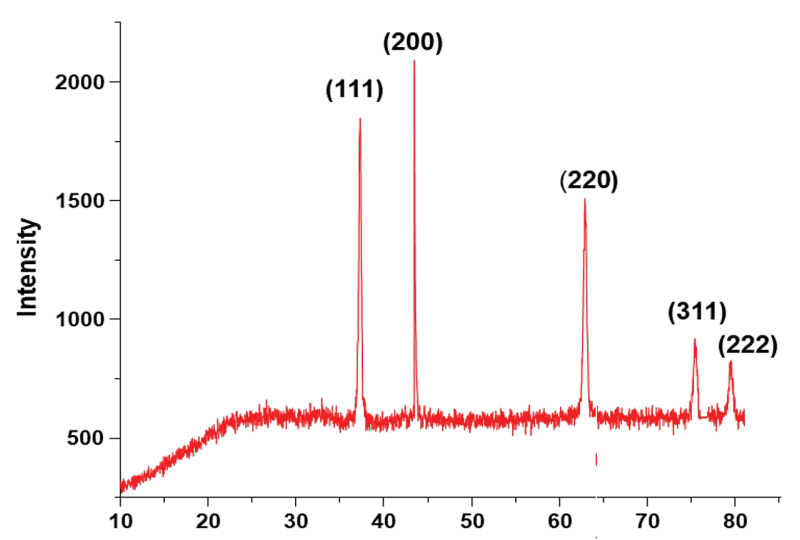

Figure 5. XRD pattern of the synthesised $\mathrm{NiO}-\mathrm{NPs}$.
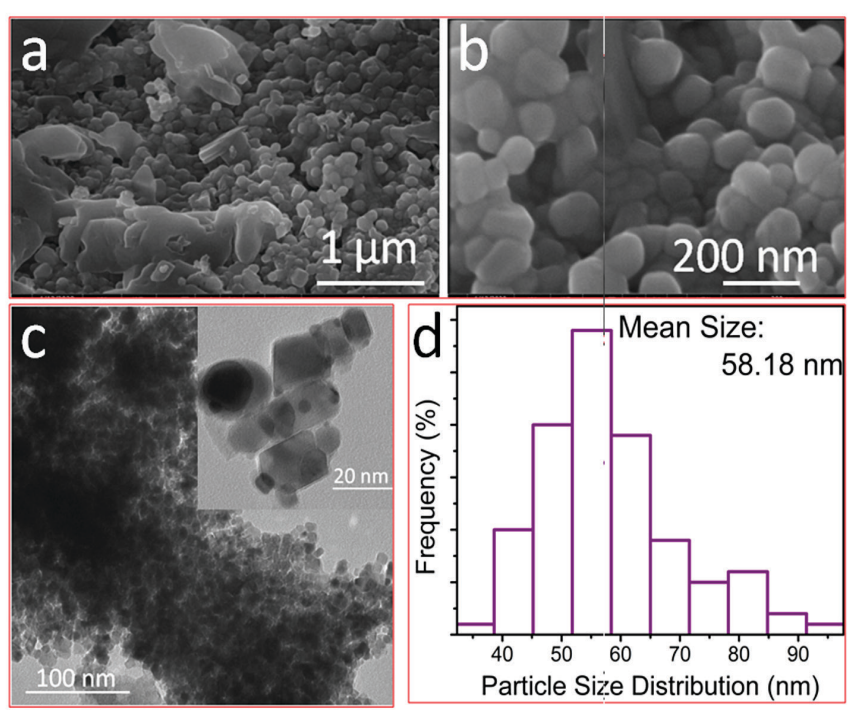

Figure 6. SEM images ( $a \& b$ ), TEM image (inset is high-resolution TEM image) (c), and particle size distribution (d) of the synthesised NiO-NPs.

calcium (Ca) and sodium (Na) (Figure 7). The Si peak in the EDX spectrum was due to the silicon from the sample grid holder. As the synthesis was conducted in ambient air, the Ni species were oxidised, thus forming $\mathrm{NiO}$ nanoparticles. The peaks in the EDX spectrum from 0 to $2 \mathrm{keV}$ revealed the successful synthesis of NiO-NPs, as reported in the literature. ${ }^{39}$ The prominent peaks observed for $\mathrm{Ni}$ and $\mathrm{O}$ showed the successful synthesis of the NiO-NPs. ${ }^{49}$ Behera et al. characterised NiO-NPs using EDX and reported the percentage of $\mathrm{Ni}$ and $\mathrm{O}$ as $77.65 \%$ and $22.35 \%$, respectively. ${ }^{24}$ 


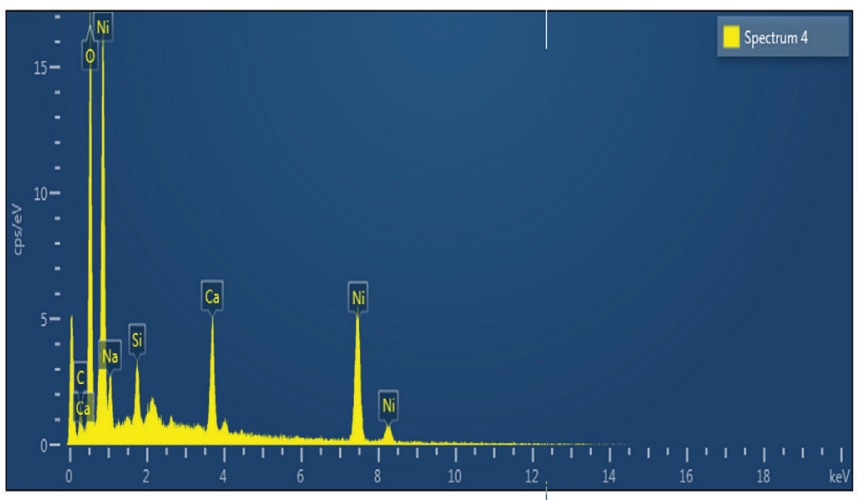

Figure 7. EDX spectrum of the synthesised NiO-NPs.

\subsection{Antibacterial Assay}

Previously, biosynthesised NiO-NPs were used to assess antifungal, anticancer and many other biological applications. ${ }^{35}$ $\mathrm{NiO}-\mathrm{NPs}$ have also been reported for their cytotoxic activities against different cells such as; human airway epithelial cell line (HEp-2). The notable cytotoxic activity of NiO-NPs against cell lines (colon cancer) was attributed to their smaller size $(9.69 \mathrm{~nm})$ and greater surface area. ${ }^{36-37}$ Helen et al. have used Moringa oleifera leaf extract to synthesise NiO-NPs. They also studied antibacterial activities against Gram-negative bacteria (E. coli) and Gram-positive bacteria (S. pneumonia and S. aureus). The inhibition zones observed were $15 \mathrm{~mm}$ with $S$. aureus, $12 \mathrm{~mm}$ with S. pneumonia, and $10 \mathrm{~mm}$ with E. coli. It was observed that the NiO-NPs were more effective in killing Gram-positive bacteria than Gram-negative bacteria. This observation revealed that the Gram-negative bacteria possess greater tolerance than the Gram-positive bacteria. ${ }^{20}$

Similarly, another study disclosed the antibacterial potential of NiO-NPs, which were synthesised from Aeglemarmelos leaf extracts. ${ }^{34}$ Din et al. explored the antibacterial potential of $\mathrm{Ni}$ and NiO-NPs. They found that the activity of these NPs against bacterium $P$. auruginosa was comparable to that of a standard antibiotic drug (Chloramphenicol). ${ }^{22}$ Stevia leaf extract has also been used to synthesise NiO-NPs that were then subjected to antibacterial studies. This study reported on antibacterial activity and noted zones of inhibition of $16 \mathrm{~mm}$ against $E$. coli. For bacterial species B. sublitis and S. pneumonia, the inhibition zones were $15 \mathrm{~mm}$ and $16 \mathrm{~mm}$, respectively. ${ }^{23}$ Behera et al. ${ }^{24}$ studied the antibacterial potential of NiO-NPs against different bacteria. They also found that NiO-NPs have higher activity against Gram-positive bacteria than Gram-negative bacteria. These researchers concluded that releasing reactive oxygen species (ROS) at the NiO-NPs interface was the most probable mechanism for killing bacteria. Backlight assay was used to find the effect of reactive oxygen species on the bacterial membrane.${ }^{38} \mathrm{Helan}$ et al. synthesised the NiO-NPs using Neem leaf extract. These researchers applied the NiO-NPs against the S. aureus and E. coli and found the inhibition zones as $13 \mathrm{~mm}$ and $15 \mathrm{~mm}$, respectively. ${ }^{39}$

Table 1. Antibacterial activities of the synthesised NiO-NPs.
In the present study, NiO-NPs were used against Gramnegative (E. coli and K. pneumonia) and Gram-positive bacteria (B. subtilis and B. lichenifermia). The synthesised NiO-NPs showed their inhibitory effect against both stains, and very clear inhibition zones were observed (Figure 8).

The results of antibacterial activity are presented in Table 1.

The synthesised NPs showed greater activities against Gram-positive bacteria and less activity against Gram-negative bacteria. The maximum activity $(28.1 \pm 1.6 \mathrm{~mm})$ was noted against Bacillus subtilis when higher concentrations of NiO-NPs $(8 \mathrm{mg} / \mathrm{ml})$ was used. When a similar concentration $(8 \mathrm{mg} / \mathrm{ml})$ of a standard antibiotic (Bacitracin) was used against Bacillus subtilis, the zone of inhibition was $25.3 \pm 2.0 \mathrm{~mm}$. Hence, $\mathrm{NiO}$ NPs were more active against Bacillus subtilis when compared to the antibiotic (Bacitracin). The minimum activity observed was $9.2 \pm 0.5 \mathrm{~mm}$ when the NiO-NPs were tested against Klebsiella pneumonia using a $2 \mathrm{mg} / \mathrm{ml}$ concentration. However, an increase in the antibacterial activities of the NiO-NPs was observed when increasing the concentration of the NPs (Table 1, Figure 8). Compared to the antibacterial results reported by different researchers, the antibacterial activity of the NiO-NPs against Populus ciliata was relatively high. This higher activity could be attributed to the small NiO-NPs $(44 \mathrm{~nm})$ size and the bonding of the bioactive molecules present in the leaf extracts of Populus ciliata. Interestingly, the activity of the leaf extracts of Populus ciliata was negligible against all the mentioned bacterial

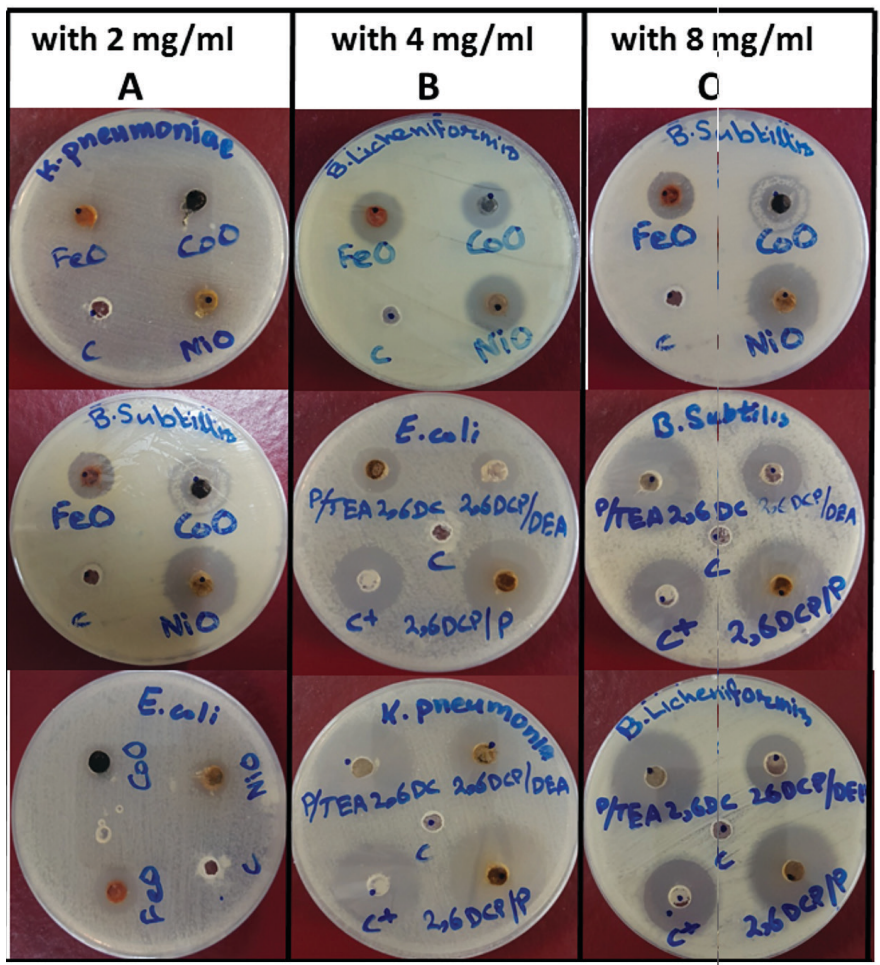

Figure 8. Images of antibacterial activities of the synthesised NiO-NPs.

\begin{tabular}{|c|c|c|c|c|c|c|c|c|c|c|}
\hline \multirow{2}{*}{$\begin{array}{l}\text { Bacterial } \\
\text { strains }\end{array}$} & \multirow[t]{2}{*}{ Bacteria } & \multirow{2}{*}{$\begin{array}{c}\text { Zones of } \\
\text { inhibition by } \\
\text { control (water) } \\
(\mathrm{mm})\end{array}$} & \multicolumn{3}{|c|}{$\begin{array}{l}\text { Zones of inhibition } \\
\text { (bacitracin) (mm) }\end{array}$} & \multirow{2}{*}{$\begin{array}{c}\text { Mean activity } \\
\text { of bacitracin } \\
\text { (with } 95 \% \mathrm{CI} \text { ) } \\
(\mathrm{mm})\end{array}$} & \multicolumn{3}{|c|}{$\begin{array}{l}\text { Zones of inhibition } \\
\text { (NiO-NPs) }(\mathrm{mm})\end{array}$} & \multirow{2}{*}{$\begin{array}{c}\text { Mean activity } \\
\text { of NiO-NPs } \\
\text { (with 95\% CI) } \\
\text { (mm) }\end{array}$} \\
\hline & & & $2 \mathrm{mg} \mathrm{ml}^{-1}$ & $4 \mathrm{mg} \mathrm{ml}^{-1}$ & $8 \mathrm{mg} \mathrm{ml}^{-1}$ & & $2 \mathrm{mg} \mathrm{ml}^{-1}$ & $4 \mathrm{mg} \mathrm{ml}^{-1}$ & $8 \mathrm{mg} \mathrm{ml}^{-1}$ & \\
\hline \multirow{2}{*}{$\begin{array}{l}\text { Gram- } \\
\text { negative }\end{array}$} & E. coli & $0 \pm 0$ & $14.5 \pm 0.5$ & $19.9 \pm 0.8$ & $23.5 \pm 1.7$ & $19.3 \pm 1.0^{*}$ & $13.2 \pm 0.4$ & $18.3 \pm 0.8$ & $22.1 \pm 0.9$ & $17.8 \pm 0.7$ \\
\hline & K. pneumoniae & $0 \pm 0$ & $12.2 \pm 0.2$ & $24.9 \pm 1.3$ & 27.2 & $21.4 \pm 1.2^{* * *}$ & 09.2 & 0.2 & 0.3 & $=0.3$ \\
\hline \multirow{2}{*}{$\begin{array}{l}\text { Gram- } \\
\text { positive }\end{array}$} & B. subtilis & $0 \pm 0$ & $9.3 \pm 0.3$ & $21.1 \pm 1.1$ & $25.3 \pm 2.0$ & $18.6 \pm 1.1$ & $15.2 \pm 0.4$ & $24.1 \pm 0.8$ & $28.1 \pm 1.6$ & $22.5 \pm 0.9^{* * *}$ \\
\hline & B. licheniformis & $0 \pm 0$ & $13.1 \pm 0.2$ & $21.2 \pm 1.5$ & $24.2 \pm 1.8$ & $19.5 \pm 1.2$ & $12.6 \pm 0.1$ & $18.5 \pm 0.9$ & $26.3 \pm 0.7$ & $19.1 \pm 0.6$ \\
\hline
\end{tabular}

Note: Each value $=$ mean $\left( \pm\right.$ SEM) of four replicates. Positive control $=$ bacitracin (antibiotic). Statistical icon: ${ }^{* *}=p \leq 0.001$. 
strains. Hence, it could be concluded that the higher activity was solely attributed to NiO-NPs.

The high antibacterial activity of the NPs may be attributed to their size, morphology, chemical composition, ability to release metal ions for trans-membrane electron transfer, penetration, oxidation of cell organelles, and production of some secondary products (reactive oxygen species ROS) that cause cell damage.$^{39}$ Gram-positive bacteria have a thicker cell wall with greater porosity and higher permeability than Gram-negative bacteria. The antibacterial activities of NPs depend on their size, stability, and concentration of NPs. The nanoscale-sized outer cell membrane of bacteria results in good reactivity towards NPs. ${ }^{40-41}$ The antibacterial activities of NiO-NPs may result from attractive electrostatic forces between negatively charged cellmembrane and positively charged $\mathrm{Ni}^{2+}$ ions. $\mathrm{The} \mathrm{Ni}^{2+}$ released from the NiO-NPs may penetrate the cell wall and damage DNA, mitochondria, protein and interrupt electron transport, resulting in cellular death. The accumulation and diffusion of $\mathrm{NiO}-\mathrm{NPs}$ in the cell membrane may change its permeability, resulting in protein leakage. ${ }^{42}$

\section{Conclusion}

The current study describes the successful synthesis of $\mathrm{NiO}-\mathrm{NPs}$ by an eco-friendly and cost-effective technique using Populus cilita leaf extract under mild conditions. Various characterisation techniques confirmed the successful synthesis of NiO-NPs; UV-Visible, FT-IR, XRD, SEM, EDX and TEM. The antibacterial activities of these NPs were evaluated against Gram-positive and Gram-negative bacteria. Higher activities were observed against Gram-positive bacteria in comparison to Gram-negative bacteria. With an increase in the concentration of NiO-NPs, the antibacterial activity of the NPs increased against all bacterial strains tested. Hence, this study highlights the potential of Populus cilitata mediated synthesis of NiO-NPs for applications against different bacterial species and could be further extended for practical applications.

\section{Acknowledgements}

The authors are grateful to Dr Muhammad Zaheer, Assistant Professor, Department of Chemistry and Chemical Engineering, LUMS, and Lahore, for extending his SEM and EDX analysis cooperation.

\section{ORCID iDs}

Muhammad Hafeez: https://orcid.org/0000-0003-0966-827X

RuzmaShaheen: https://orcid.org/0000-0001-7029-0531

Bilal Akram: https://orcid.org/0000-0001-7668-3061

Muhammad Naeem Ahmed: https://orcid.org/0000-0002-5559-1763

Zain-ul-abdin: https://orcid.org/0000-0002-1653-2111

Sirajul Haq: https://orcid.org/0000-0002-9424-2531

Salah ud din: https://orcid.org/0000-0002-4450-7431

Maryum Zeb: https://orcid.org/0000-0002-3091-5397

Muhammad Abdullah Khan: https://orcid.org/0000-0003-2500-8036

\section{References}

1 V. Colvin, M. Schlamp and A. P. Alivisatos, Light-emitting diodes made from cadmium selenide nanocrystals and a semiconducting polymer, Nature, 1994, 370, 354-365.

2 Y. Wang and N. Herron, Nanometer-sized semiconductor clusters: materials synthesis, quantum size effects, and photophysical properties, J. Phys. Chem., 1991, 95, 525-532.

3 G. Schmid, Large clusters and colloids, metals in the embryonic state, Chem. Rev.,1992, 92, 1709-1727.

4 A. J. Hoffman, G. Mills, H. Yee and M. R. Hoffman, Q-sized cadmium sulfide: synthesis, characterisation and efficiency of photoinitiation of polymerisation of several vinylic monomers. J. Phys. Chem.,1992, 96, 5546-5552.
5 Y. Wang, Nonlinear optical properties of nanometer-sized semiconductor clusters, Accounts Chem. Res., 1991, 24, 133-139.

6 H. S. Mansur, F. Grieser, M. S. Marychurch, S. Biggs, R. S. Urquhart and D. N. Furlong, Photoelectrochemical properties of Q-state CdS particles in arachidic acid Langmuir-Blodgett films, J. Chem. Soc. Farad. T., 1991, 91, 665-672.

7 S. Panigrahi, S. Kundu, S. Ghosh, S. Nath and T. Pal, General method of synthesis for metal nanoparticles, J. Nanopart. Res., 2004, 6, 411414.

8 K. N. Thakkar, S. S. Mhatre, and R.Y. Parikh, Biological synthesis of metallic nanoparticles. Nanomed. Nanotechnol. Bio. E Med., 2010, 6, $257-262$.

9 M. Sorbiun, E. S. Mehr, A. Ramazani and A. M. Malekzadeh, Biosynthesis of metallic nanoparticles using plant extracts and evaluation of their antibacterial properties. Nanochem Res., 3, 1-16.

10 B. Sasi, K. G. Gopchandran and P. K. Manoj, Studies on nanocrystalline nickel oxide thin films for potential applications, Mater. Today Proceedings, 2017, 4, 4123-4129.

11 S. Sudhasree, A. S. Banu, P. Brindha and G.A. Kurian, Synthesis of nickel nanoparticles by chemical and green route and their comparison in respect to biological effect and toxicity. ToxicoleEnvironm. Chem., 2014, 96, 743-754.

12 R. Joerger, T. Klaus and C. G. Granqvist, Biologically produced silver-carbon composite materials for optically functional thin-film coatings, Adv. Mater., 2000, 12, 407-409.

13 N. Gong, K. Shao, W. Feng, Z. Lin, C. Liang and Y. Sun, Biotoxicity of nickel oxide nanoparticles and bio-remediation by microalgae Chlorella Vulgaris. Chemosphere, 2011, 83, 510-516.

14 M. P. Abbracchio, J. Simmons-Hansen and M. Costa, Cytoplasmic dissolution of phagocytised crystalline nickel sulfide particles: a prerequisite for nuclear uptake of nickel, J. Toxicol. E Environ. Health., 1982, 9, 663-676.

15 O. V. Kharissova, H. V. R. Dias, B. I. Kharisov, B. O. Perez and V. M. J. Perez, The greener synthesis of nanoparticles, Trends Biotechnol., 2013, 31, 240-248.

16 D. Nath and P. Banerjee, Green nanotechnology a new hope for medical biology, Environ. Toxicol. EPharmacol., 2013, 36, 997-1014.

17 R. S. Varma, Greener approach to nanomaterials and their sustainable applications, Curr. Opin. Chem. Eng., 2012, 1, 123-128.

19 P. Raveendran, J. Fu and S. L. Wallen, Completely, "Green" synthesis and stabilisation of metal nanoparticle, J. Am. Chem. Soc., 2003, 125, 13940-13941.

20 A. A. Ezhilarasi, J. J. Vijaya, K. Kaviyarasu, L. J. Kennedy, R. J. Ramalingam and H. A. Al-Lohedan, Green synthesis of $\mathrm{NiO}$ nanoparticles using Moringaoleifera extract and their biomedical applications: Cytotoxicity effect of nanoparticles against HT-29 cancer cells, J. Photochem. Photobiol. B, Biol., 2016, 164, 352-360.

21 I. W. Sutherland, Biofilm exopolysaccharides: a strong and sticky framework. Microbiol., 2001, 147, 3-9.

22 M. I. Din, A. G. Nabi, A. Rani, A. Aihetasham and M. Mukhtar, Single step green synthesis of stable nickel and nickel oxide nanoparticles from Calotropisgigantea: Catalytic and antimicrobial potentials, Environ. Nanotechnol. Monitor. EManag., 2018, 9, 29-36.

23 S. Srihasam, K. Thyagarajan, M. Korivi, V. R. Lebaka and S. P. R. Mallem, Phytogenic generation of $\mathrm{NiO}$ nanoparticles using Stevia leaf extract and evaluation of their in-vitro antioxidant and antimicrobial properties, Biomolecules, 2020, 10, 89-101.

24 N. Behera, M. Arakha, M. Priyadarshinee, B. S. Pattanayak, S. Soren, S. Jha and B. C. Mallick, Oxidative stress generated at nickel oxide nanoparticle interface results in bacterial, membrane damage leading to cell death, RSC Adv., 2019, 9, 24 888-24 894.

25 V. Helan, J. J. Prince, N. A. Al-Dhabi, M. V. Arasu, A. Ayeshamariam, G. Madhumitha, S. M. Roopan and M. Jayachandran, Neem leaves mediated preparation of $\mathrm{NiO}$ nanoparticles and its magnetisation, coercivity and antibacterial analysis, Results Phys., 2016, 6, 712-718.

26 G. Basak, D. Das and N. Das, Dual role of acidic diacetatesophorolipid as biostabilizer for $\mathrm{ZnO}$ nanoparticle synthesis and biofunctionalizing agent against Salmonella enterica and Candida albicans. J. Microbiol. Biotechnol., 2014, 24, 87-96. 
27 A. Nel, T. Xia, L. Mädler and N. Li, Toxic potential of materials at the nanolevel, Science, 2006, 311, 622-627.

28 A. Simon-Deckers, S. Loo, M. Mayne-Lhermite, N. Herlin-Boime, N. Menguy, C. Reynaud and M. Carriere, Size, composition-and shapedependent toxicological impact of metal oxide nanoparticles and carbon nanotubes toward bacteria. Environ. Sci. E technol., 2009, 43, 8423-8429.

29 Y. W. Baek and Y. J. An, Microbial toxicity of metal oxide nanoparticles $\left(\mathrm{CuO}, \mathrm{NiO}, \mathrm{ZnO}\right.$, and $\left.\mathrm{Sb}_{2} \mathrm{O}_{3}\right)$ to Escherichia coli, Bacillus subtilis, and Streptococcus aureus, Sci. Total Environ., 2011, 409, 1603-1608.

30 K. K. Wong and X. Liu, Silver nanoparticles-the real "silver bullet" in clinical medicine? Med. Chem. Comm., 2010, 1, 125-131.

31 M. A. Nasseri, F. Ahrari and B. Zakerinasab, A green biosynthesis of $\mathrm{NiO}$ nanoparticles using aqueous extract of Tamarixserotina and their characterisation and application, Appl. Organomet. Chem., 2016, 30, 978-984.

32 M. I. Din and A. Rani, Recent advances in the synthesis and stabilisation of nickel and nickel oxide nanoparticles: A green adeptness, Int. J. Anal. Chem., 2016, 4, 1-14.

33 C. J. Pandian, R. Palanivel and S. Dhananasekaran, Green synthesis of nickel nanoparticles using Ocimum sanctum and their application in dye and pollutant adsorption, Chin. J. Chem. Eng., 2015, 23, 13071315.

34 G. Angajala, R. Ramya and R. Subashini, In-vitro anti-inflammatory and mosquito larvicidal efficacy of nickel nanoparticles phytofabricated from aqueous leaf extracts of Aegle marmelos Correa, 2014, Acta Trop., 135, 19-26.
35 R. Yuvakkumar, J. Suresh, A. J. Nathanael, M. Sundrarajan and S. I. Hong, Rambutan (Nepheliumlappaceum) peel extract assisted biomimetic synthesis of nickel oxide nanocrystals, Mater. Lett., 2014, 128, 170-174.

36 M. Hafeez, R. Arshad, M. U. Hameed, B. Akram, M. N. Ahmed, S. A. Kazmi, I. Ahmad and S. Ali, Populusciliata leaves extract mediated synthesis of zinc oxide nanoparticles and investigation of their antibacterial activities, Mater. Res. Express, 2019, 6, 1-8.

37 M.Hafeez, R. Arshad, J. Khan, B. Akram, M. N. Ahmad, M.U. Hameed and S. Haq, Populusciliata mediated synthesis of copper oxide nanoparticles for potential biological applications, Mater. Res. Express, 2019, 5, 1-8.

38 V. Helan, J. J. Prince, N. A. Al-Dhabi, M. V. Arasu, A. Ayeshamariam, G. Madhumitha, S. M. Roopan and M. Jayachandran, Neem leaves mediated preparation of $\mathrm{NiO}$ nanoparticles and its magnetisation, coercivity and antibacterial analysis, Results Phys., 2016, 6, 712-718.

39 G. Basak, D. Das, N. Das, Dual role of acidic diacetatesophorolipid as biostabilizer for $\mathrm{ZnO}$ nanoparticle synthesis and biofunctionalizing agent against Salmonella enterica and Candida albicans, J. Microbiol. Biotechnol., 2014, 24, 87-96.

40 A. Nel, T. Xia, L. Mädler, N. Li, Toxic potential of materials at the nano level Science., 2006, 311, 622-627.

41 Y. W. Baek and Y. J. An, Microbial toxicity of metal oxide nanoparticles $\left(\mathrm{CuO}, \mathrm{NiO}, \mathrm{ZnO}\right.$, and $\left.\mathrm{Sb}_{2} \mathrm{O}_{3}\right)$ to Escherichia coli, Bacillus subtilis, and Streptococcus aureus, Sci. Total Environ., 2011, 409, 1603-1608.

$42 \mathrm{~K}$. K. Wong, X. Liu, Silver nanoparticles-the real "silver bullet" in clinical medicine? Med. Chem. Comm., 2010, 1, 125-131. 